\title{
The comparison of dual axis photovoltaic tracking system using artificial intelligence techniques
}

\author{
Machrus Ali ${ }^{1}$, Aji Akbar Firdaus ${ }^{2}$, Hamzah Arof ${ }^{3}$, Hidayatul Nurohmah ${ }^{4}$, Hadi Suyono $^{5}$, \\ Dimas Fajar Uman Putra ${ }^{6}$, Muhammad Aziz Muslim ${ }^{7}$ \\ ${ }^{1,4}$ Department of Electrical Engineering, Darul Ulum University, Indonesia \\ ${ }^{2}$ Department of Engineering, Universitas Airlangga, Surabaya, Indonesia \\ ${ }^{3}$ Department of Electrical Engineering, University of Malaya, Kuala Lumpur, Malaysia \\ ${ }^{5,7}$ Department of Electrical Engineering, Brawijaya University, Malang, Indonesia \\ ${ }^{6}$ Department of Electrical Engineering, Institut Teknologi Sepuluh Nopember, Surabaya, Indonesia
}

\section{Article Info \\ Article history: \\ Received Aug 27, 2020 \\ Revised Sep 13, 2021 \\ Accepted Sep 30, 2021}

\section{Keywords:}

Bat algorithm

Dual axis photovoltaic tracking

system

PID controller

\begin{abstract}
In this paper, the efficiency of photovoltaic panels is improved by adding a sun tracking system. The solar tracking system is used for tracking the sun so that photovoltaic always faces the sun. This system uses a dual axis consisting of horizontal rotation axis and a vertical rotation axis. The horizontal rotational axis motion is to follow the azimuth angle of the sun from north to south. Then, to follow the sun's azimuth angle from east to west is the vertical axis motion. Both types of movements are controlled using a PID controller that is optimized with an artificial intelligence approach, namely particle swarm optimization (PID-PSO), firefly algorithm (PID-FA), imperialist competitive algorithm (PID-ICA), bat algorithm (PID-BA), and ant colony optimization (PID-ACO). Experiments of various approaches were carried out and the corresponding performance compared. The experimental results show that PID-BA performs best in terms of settling time and overshoot. The results also allow the comparison of different PID controller and the calculation of the fastest completion time.
\end{abstract}

This is an open access article under the CC BY-SA license.

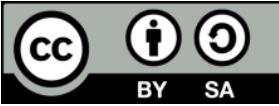

\section{Corresponding Author:}

Aji Akbar Firdaus

Department of Engineering

Universitas Airlangga

Dharmawangsa Dalam Road, 60286, Surabaya, Indonesia

Email: aa.firdaus@ vokasi.unair.ac.id

\section{INTRODUCTION}

The use of renewable energy such as solar energy and wind energy is very fast [1]-[4]. However, solar energy is very promising to be used as electricity generation [5]. Several techniques have been done to obtain optimal electricity using photovoltaics. One of the techniques to get electric power is the addition of tracking control systems to photovoltaic (PV) systems. It has been added to obtain the maximum power point from the PV and direct the PV towards the sun. Tracking power point in a photovoltaic system has been investigated to track the PV system's maximum power points using the fuzzy logic controller [6], [7]. Solar panels also need control of tracking the position of the sun so that they always precisely follow the position of the sun. This solar tracking system is used to track the horizontal rotation axis and vertical rotation axis [8], [9]. The horizontal axis is the axis used to track the sun's height angle and the vertical axis is the axis following the angle of the sun's azimuth. Control optimization is needed so that the position is exactly as desired.

A study which was conducted by [10], [11] analyzed about the benefits of using sun-tracking versus using fixed modules. They concluded that there was a gain of 30-50\% higher than using fixed modules. In 
need of that best performance of that gain then the authors proposed an empirical study on comparing several artificial intelligence methods that will be used on the experiment. These artificial methods will optimize the movement of PID controller. Artificial intelligence (AI) has been often used in system optimization and has contributed a lot to research. Among them are used for control and optimization of vehicle steer [12], controls on motor speed, frequency control on micro-hydro [8], speed control on wind turbines, and dual axis tracking photovoltaic control. The artificial intelligence method used is particle swarm optimization (PSO) [13], firefly algorithm (FA) [14], imperialist competitive algorithm (ICA) [15], [16], bat algorithm (BA) [17], and ant colony optimization (ACO) [18]. In this paper, PID-PSO, PID-FA, PID-ICA, PID-BA, and PID-ACO are used to track sunlight to get the maximum power point from PV. For optimization often used artificial intelligence to get the best optimization automatically [13] but it has different result of each artificial methods. In this study, several methods chosen to carry out in this research were PSO, FA, dan fuzzy logic controller (FLC). Those methods will be tested and measured to discover best result among methods so that they will obtain maximum power point. The results also allow the comparison of different PID controller and the calculation of the fastest completion time.

\section{DUAL AXIS TRACKING MODEL}

Solar-azimuth-elevation tracking consistsiof a horizontal rotation axis to track the sun's height $(\alpha)$ from north to south and a vertical axis of rotation to track the sun's azimuth angle $(\gamma)$ from east to west as shown in Figure 1. The azimuth angle is the angle formed by the sun clockwise from north to south [19]. The azimuth angle depends on the latitude and time of the year and has an equation like (1) [20]. The elevation angle is the horizontal angle of the sun. The angle of the sun's height dependsion the latitude and time of the year like (2).

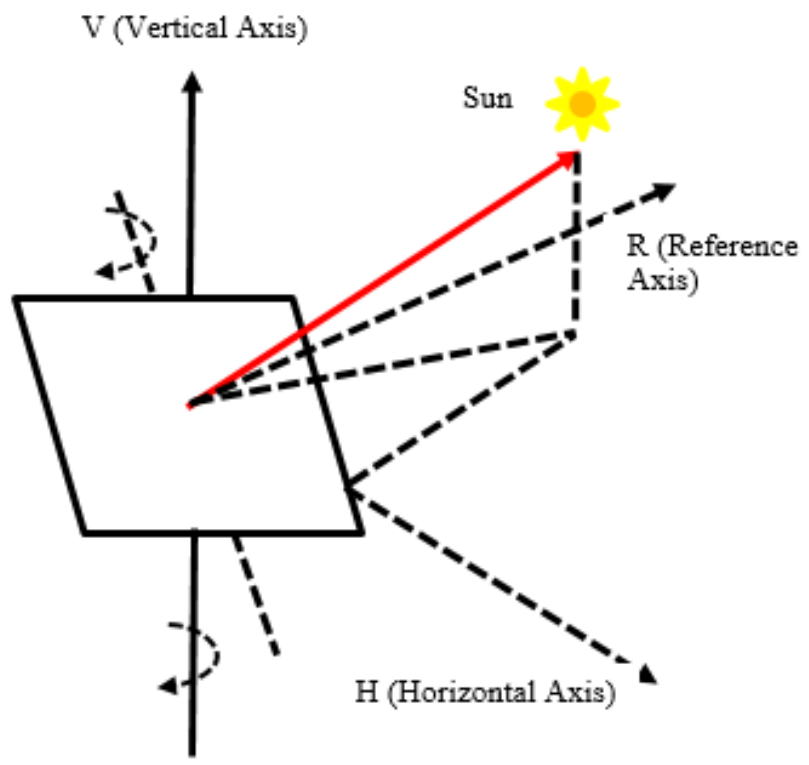

Figure 1. Two-axis solar tracking [10]

$$
\begin{aligned}
& y=\arccos \left\{\frac{\sin \delta \cos \varphi-\cos \delta \sin \varphi \cos H R A}{\cos a}\right\} \\
& \alpha=\arcsin (\sin \delta \sin \varphi-\cos \delta \cos \varphi \cos (H R A))
\end{aligned}
$$

\subsection{Parameters of system}

This research was conducted in Indonesia with DC motor parameters such as Table 1, and spur gear parameters like Table 2. Table 3 is the PV model parameters. 
Table 1. The parameters of DC motor

\begin{tabular}{cc}
\hline DC motori Parameters & Value \\
\hline J $\left(\right.$ kg.m $\left.{ }^{2}\right)$ & $3.2284 \times 10^{-6}$ \\
b $(\mathrm{N} . m . s)$ & $3.5077 \times 10^{-6}$ \\
kb $\left(\right.$ Vsec.rad $\left.{ }^{-1}\right)$ & 0.0274 \\
kt $\left(\right.$ Nm.Amp $\left.{ }^{-1}\right)$ & 0.0274 \\
R $(\Omega)$ & 4 \\
L $(\mathrm{H})$ & $2.75 \times 10^{-6}$ \\
\hline
\end{tabular}

Table 2. Spur gear

\begin{tabular}{ccc}
\hline Type & Number of teeth & Mass (gr) \\
\hline M1B12 model & 12 & 10 \\
M1A20 model & 120 & 1320 \\
\hline
\end{tabular}

Table 3. NPS100W PV model

\begin{tabular}{cc}
\hline PV parameters & Value \\
\hline Dimension(mm) & 10 \\
Mass $(\mathrm{kg})$ & 1320 \\
$\mathrm{~J} 1\left(\mathrm{~kg} \cdot \mathrm{m}^{2}\right)$ & 0.0022642 \\
JT1 $\left(\mathrm{kg} \cdot \mathrm{m}^{2}\right)$ & 0.0023185 \\
J2 $\left(\mathrm{kg} \cdot \mathrm{m}^{2}\right)$ & 0.0222231 \\
JT2 $\left(\mathrm{kg} \cdot \mathrm{m}^{2}\right)$ & 0.0222774 \\
\hline
\end{tabular}

\subsection{DC motor model}

By using the transform of Laplace, (4) is DC Motor model without load.

$$
\begin{aligned}
& \mathrm{LsI}(\mathrm{s})+\mathrm{RI}(\mathrm{s})=\mathrm{V}(\mathrm{s})-\mathrm{Ks} \theta(\mathrm{s}) \\
& \frac{\theta(\mathrm{s})}{\mathrm{V}(\mathrm{s})}=\frac{\mathrm{K}}{\mathrm{s}\left((\mathrm{Js}+\mathrm{b})(\mathrm{Ls}+\mathrm{R})+\mathrm{K}^{2}\right)} \\
& \frac{\theta(\mathrm{s})}{\mathrm{V}(\mathrm{s})}=\frac{0.0274}{8.878 \times 10^{-12} \mathrm{~s}^{3}+1.291 \mathrm{~s}^{2}+0.0007647308 \mathrm{~s}}
\end{aligned}
$$

\subsection{Horizontal axis model}

The inertia moment of the solar cell and the turning angle acceleration affects the torque value of photovoltaic loads. As shown in (9) is the inertia moment of the horizontal axis rotary sun. Tracking the horizontal axis rotary sun like (10).

$$
\begin{aligned}
& \mathrm{J}_{1}=\frac{1}{2} \mathrm{~m}_{\mathrm{pv}} \mathrm{L}^{2}\left(\frac{\mathrm{N}_{2}}{\mathrm{~N}_{1}}\right)^{2}\left[\mathrm{~kg} \cdot \mathrm{m}^{2}\right] \\
& \mathrm{J}_{\mathrm{T} 1}=\mathrm{J}_{\mathrm{st}}+\mathrm{J}_{1}\left[\mathrm{~kg} \cdot \mathrm{m}^{2}\right] \\
& \mathrm{J}_{\mathrm{T} 1}=2.71684 \times 10^{-5}+\mathrm{J}_{1}\left[\mathrm{~kg} \cdot \mathrm{m}^{2}\right] \\
& \frac{\theta(\mathrm{s})}{\mathrm{V}(\mathrm{s})} \mathrm{i}=\frac{\mathrm{K}}{\mathrm{s}\left((\mathrm{JT} 1 \mathrm{~s}+\mathrm{b})(\mathrm{Ls}+\mathrm{R})+\mathrm{K}^{2}\right)} \\
& \frac{\theta(\mathrm{s})}{\mathrm{V}(\mathrm{s})} \mathrm{i}=\frac{0.0274}{6.375875 \times 10^{-9} \mathrm{~s}^{3}+0.009274 \mathrm{~s}^{2}+0.0007647308 \mathrm{~s}}
\end{aligned}
$$

\subsection{Vertical axis model}

As shown in (11) represents the inertia moment of a vertical rotary axis. The inertia moment of the vertical rotary axis of the PV tracker is (14) and the transfer function of the vertical rotary axis solar track tracker is (15).

$$
\begin{aligned}
& \mathrm{J}_{1}=\frac{1}{2} \mathrm{~m}_{\mathrm{pv}}\left(\mathrm{L}^{2}+\mathrm{W}^{2}\right)\left(\frac{\mathrm{N}_{2}}{\mathrm{~N}_{1}}\right)^{2}\left[\mathrm{~kg} \cdot \mathrm{m}^{2}\right] \\
& \mathrm{J}_{\mathrm{T} 2}=\mathrm{J}_{\mathrm{st}}+\mathrm{J}_{2}\left[\mathrm{~kg} \cdot \mathrm{m}^{2}\right] \\
& \mathrm{J}_{\mathrm{T} 2}=2.71684 \times 10^{-5}+\mathrm{J}_{2}\left[\mathrm{~kg} \cdot \mathrm{m}^{2}\right] \\
& \frac{\theta(\mathrm{s})}{\mathrm{V}(\mathrm{s}) \mathrm{i}}=\frac{\mathrm{K}}{\mathrm{s}\left((\mathrm{JT} 2 \mathrm{~s}+\mathrm{b})(\mathrm{Ls}+\mathrm{R})+\mathrm{K}^{2}\right)}
\end{aligned}
$$


$\frac{\theta(\mathrm{s})}{\mathrm{V}(\mathrm{s}) \mathrm{i}}=\frac{0.0274}{6.126285 \times 10^{-8} \mathrm{~s}^{3}+9.646175 \times 10^{-6} \mathrm{~s}^{2}+0.00075076 \mathrm{~s}}$

\subsection{PID controller}

PID controller is a simple controller that has three controller parameters, namely proportional (Kp), integra $1(\mathrm{Ki})$, and derivative (Kd) gain. The PID controller can be tuned using the Ziegler-Nichols method, using the self-tuning method, and using the artificial intelligence method [21].

\subsection{Particle swarm optimization (PSO)}

The PSO is an optimization algorithm that mimics the collective behavior of birds [22], [23]. In this paper, optimization is done to find the PID parameters value so that the PID can produce azimuth angles and sun elevation angles. So that the $\mathrm{PV}$ can produce maximum power points. The parameters of PSO are shown in Table 4.

\subsection{Firefly algorithm (FA)}

The FA algorithm is an optimization algorithm that mimics the collective behavior of fireflies [24], [25]. In this paper, PID parameters are searched by using FA so that PID can produce azimuth angles and sun altitude angles. So that the maximum power point is obtained. The FA parameters are shown in Table 5.

Table 4. Parameters of PSO

\begin{tabular}{cc}
\hline PSO Parameters & Value \\
\hline Number of Particles & 30 \\
Maximum of iteration & 50 \\
Number of Variables & 3 \\
C2 (Constant of Social) & 2 \\
C1 (Constant of Cognitive) & 2 \\
W (Inertia Momentum) & 0.9 \\
Kph_pso, Kpv_pso & $0-300$ \\
Kih_pso, Kiv_pso & $0-100$ \\
Kdh_pso, Kdv_pso & $0-100$ \\
\hline
\end{tabular}

Table 5. Parameters of FA

\begin{tabular}{cc}
\hline FA Parameters & Value \\
\hline Alpha $(\alpha)$ & 0.25 \\
Beta $(\beta)$ & 0.2 \\
Gamma $(\gamma)$ & 1 \\
Dimensi & 3 \\
Fireflies Number & 50 \\
Maximum of iteration & 50 \\
Kph_fa, Kpv_fa & $0-300$ \\
Kih_fa, Kiv_fa & $0-100$ \\
Kdh_fa, Kdv_fa & $0-100$ \\
\hline
\end{tabular}

\subsection{Imperialist competitive algorithm (ICA)}

The ICA is an optimization algorithm that mimics socio-political behavior [15]. In this paper, ICA is used to determine PID parameters, then PID will determine the azimuth and the sun's height angle. So that the maximum power point is obtained. The parameters of ICA are shown in Table 6.

Table 6. Parameters of ICA

\begin{tabular}{cc}
\hline ICA-Parameters & Value \\
\hline Countries Number & 50 \\
Imperialists Number & 6 \\
Colonies Number & 44 \\
Revolution rate & 0.3 \\
Coefficient of Assimilation $(\beta)$ & 2 \\
Coefficient of Assimilation $(\gamma)$ & 0.5 \\
Zeta $\zeta$ & 0.01 \\
Kph_ica, Kpv_ica & $0-300$ \\
Kih_ica,Kpv_ica & $0-100$ \\
Kdh_ica, Kdv_ica & $0-100$ \\
\hline
\end{tabular}

\subsection{Bat algorithm (BA)}

Bat algorithm (BA) is a stochastic global optimization algorithm based on bat echolocation mechanism and very good characteristics [26], [27]. Some simulation results show that the bat algorithm model has a good performance in the optimization function. The parameters of BA are shown in Table 7.

\subsection{Ant colony optimization (ACO)}

ACO is algorithm that mimic the behavior of dead ants and sort the ant's larvae. The ACO algorithm provides relevant partitions of data without the knowledge of the initial cluster center. There are ant agents that randomly move on two-dimensional grids where in the grid there are randomly scattered objects, and the size of the grid depends on the number of objects. Ant agents that are selected or allowed to 
move in the grid, will take objects and also drop objects that are affected by the similarity and density of objects [28]. The standard ACO used are shown in Table 8.

Table 7. Parameters of BA

\begin{tabular}{cc}
\hline BA Parameters & Value \\
\hline Population Size & 35 \\
Noise / Loudness & 0.5 \\
Pulse / Pulse rate ratio & 0.6 \\
Alpha $(\alpha)$ & 0.9 \\
Gamma $(\gamma)$ & 0.9 \\
Amount of Iteration & 50 \\
Kph_ba, Kpv_ba & $0-300$ \\
Kih_ba, Kiv_ba & $0-100$ \\
Kdh_ba, Kdv_ba & $0-100$ \\
\hline
\end{tabular}

Table 8. Parameters of ACO

\begin{tabular}{cc}
\hline ACO Parameters & Value \\
\hline Node & 100 \\
Max_It & 50 \\
Alpha $(\alpha)$ & 1 \\
Beta $(\beta)$ & 2 \\
Rho & 0.1 \\
C & 100 \\
Kph_aco, Kpv_aco & $0-300$ \\
Kih_aco, Kiv_aco & $0-100$ \\
Kdh_aco,Kdv_aco & $0-100$ \\
\hline
\end{tabular}

\section{RESULTS AND DISCUSSION}

The sun's declination is the angle between the equator and the line drawn from the center of the earth to the center of the sun. Solar declination results in four seasons in the subtropical regions of both the northern hemisphere and the southern hemisphere. Transfer function is made into MATLAB simulink equation as follows. Control design of motor DC without load by design, uncontrolled, PID-PSO, PID-FA, PID-ICA, PID-BA, and PID-ACO as shown in Figure 2. Design PID Controller for the simulation of dual axis shown in Figure 3, while designs of uncontrolled, PID-PSO, PID-FA, PID-ICA, PID-BA, and PIDACO shown in Figure 4. Angular response results motor DC; Uncontrolled, PID-PSO, PID-FA, PID-ICA, PID-BA, and PID-ACO shown in Figure 5, Horizontal Axis; Uncontrolled, PID-PSO, PID-FA, PID-ICA, PID-BA, and PID-ACO shown in Figure 6, and Angular Vertical Response Axis; uncontrolled, PID-PSO, PID-FA, PID-ICA, PID-BA, and PID-ACO shown in Figure 7. The results of the assessment in detail shows in Tables 9-11.

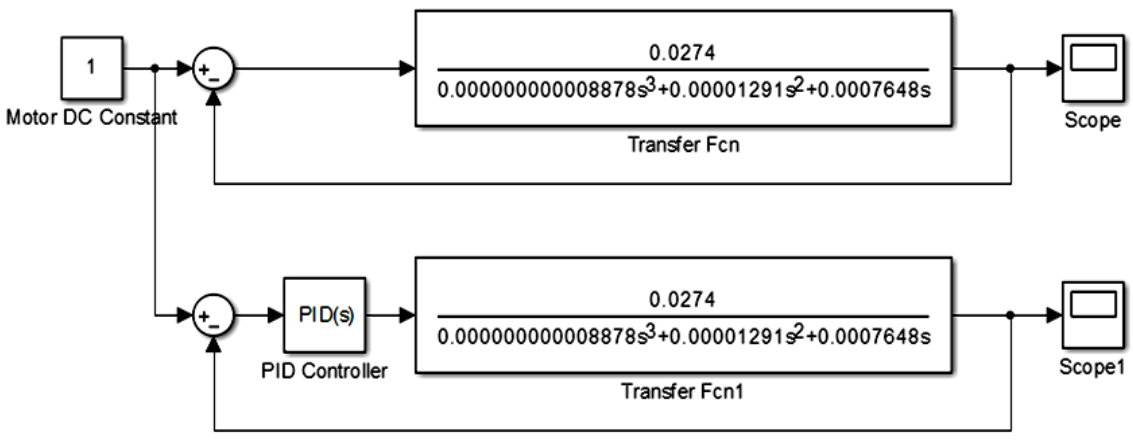

Figure 2. Design control of motor DC without load

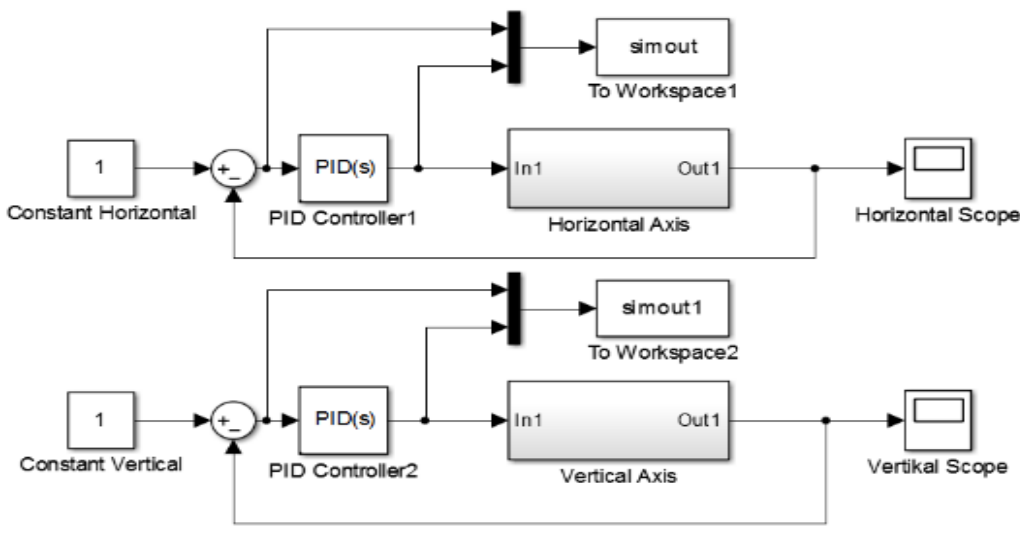

Figure 3. Design of PID controller for dual axis simulation 


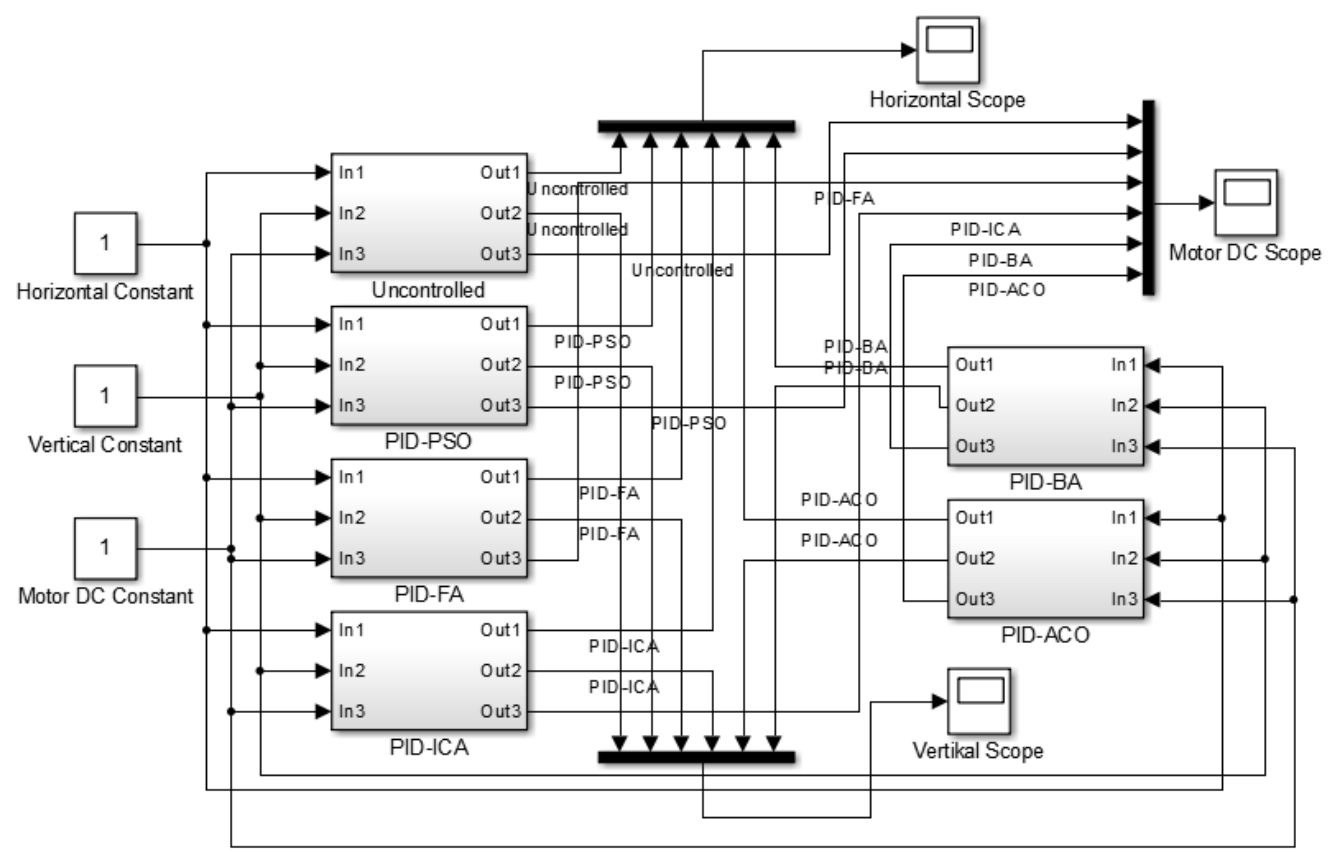

Figure 4. Design of dual axis control at PV

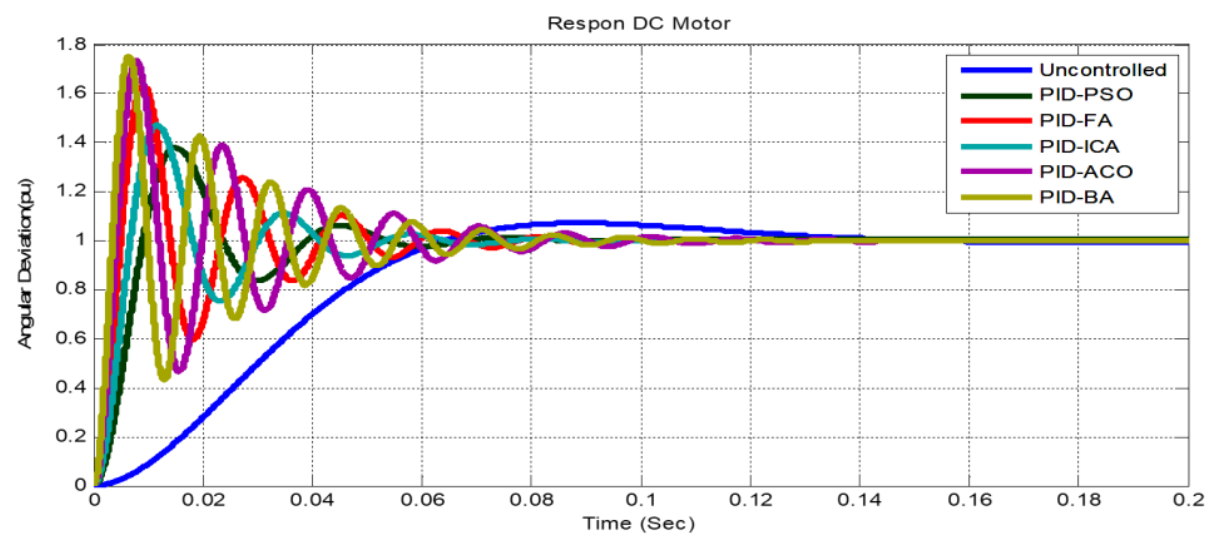

Figure 5. Respons Motor DC

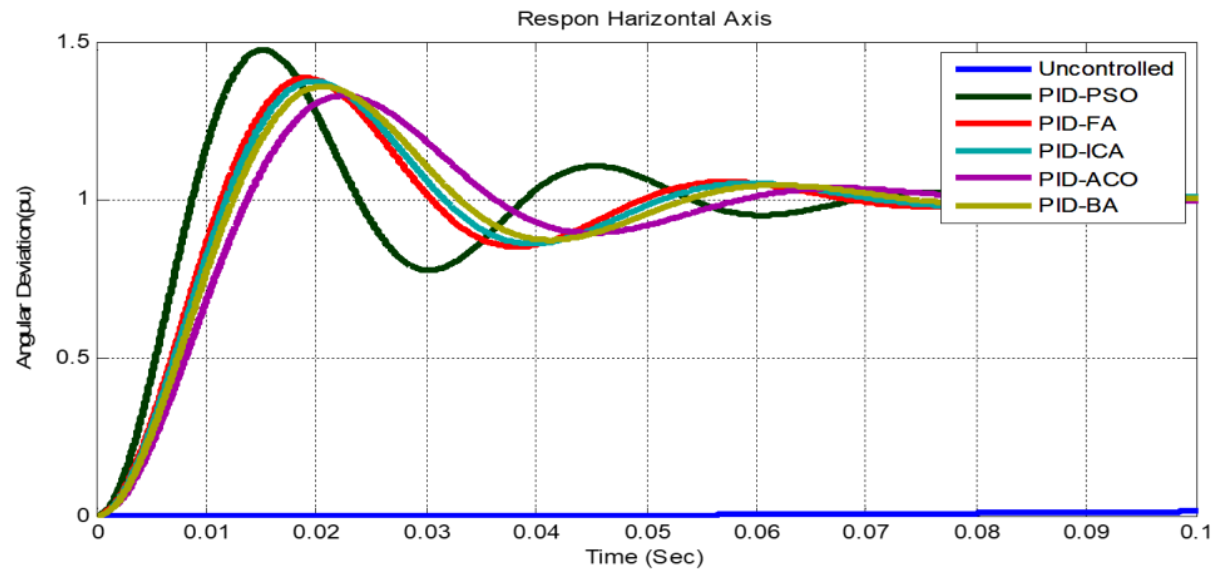

Figure 6. Angular respons horizontal axis 


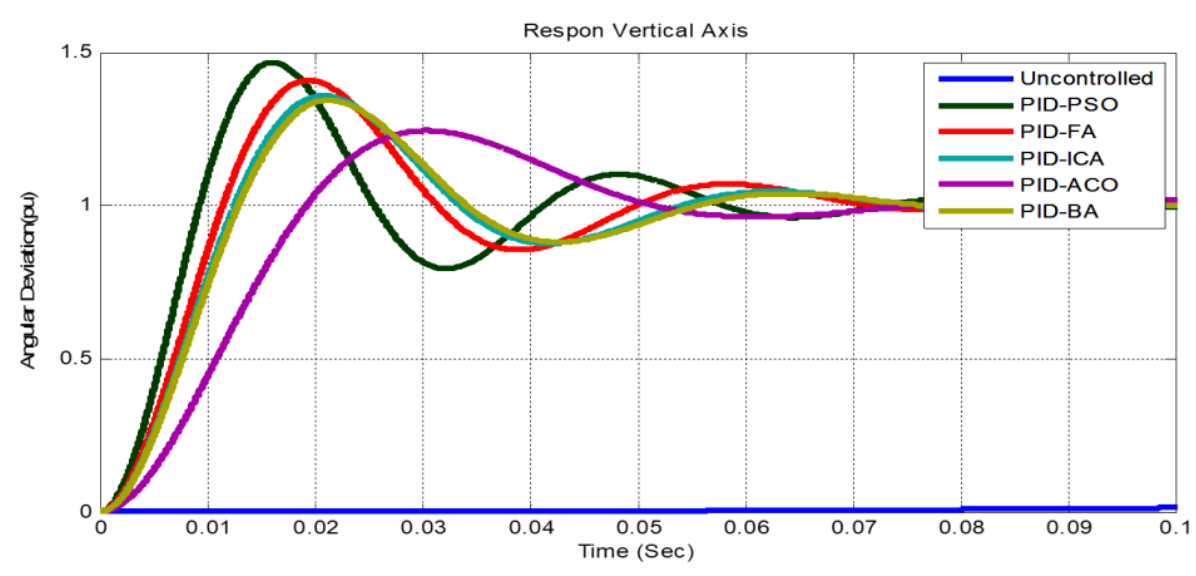

Figure 7. Angular respons vertical axis

The motor DC response results in Table 9 can be explained that of the 6 models, the worst model in tracking the position of the sun is an uncontrolled model. The highest overshoot value in PID-PSO is 1.754 $\mathrm{pu}$ and the lowest value in PID-ICA is $1.271 \mathrm{pu}$. The highest undershoot value in the PID-ACO is $0.836 \mathrm{pu}$ and the lowest value in uncontrolled is $0.005 \mathrm{pu}$. The PID-ICA undershoot lasts only 0.001 seconds. The fastest completion time on PID-ICA is $0.143 \mathrm{~s}$ and the longest in uncontrolled is $1.442 \mathrm{~s}$.

Table 9. Motor DC results

\begin{tabular}{ccccccc}
\hline & Unc & PID-PSO & PID-FA & PID-ICA & PID-BA & PID-ACO \\
\hline Kpm & - & 8.468 & 34.145 & 13.499 & 60.203 & 79.487 \\
Kim & - & 14.908 & 3.079 & 1.353 & 9.845 & 7.326 \\
Kdm & - & 0.133 & 0.231 & 0.220 & 0.163 & 0.325 \\
Overshoot (pu) & 1.072 & 1.754 & 1.636 & 1.271 & 1.734 & 1.378 \\
Undershoot (pu) & 0.005 & 0.566 & 0.596 & 0.246 & 0.534 & 0.836 \\
Settling time (s) & 1.442 & 0.322 & 0.184 & 0.143 & 0.173 & 0.193 \\
\hline
\end{tabular}

The horizontal response results in Table 10 can be explained that of the 8 models, the worst model in tracking the position of the sun is an uncontrolled model. The highest overshoot value in PID-PSO is $49.100 \mathrm{pu}$ and the lowest value in PID-BA is $25.912 \mathrm{pu}$. The highest undershoot value in the uncontrolled is $22.300 \mathrm{pu}$ and the lowest value in PID-ACO is $10.473 \mathrm{pu}$. The PID-BA undershoot only lasts 0.019 seconds with a small difference in value, so it can be ignored. The fastest completion time on PID-BA is $0.241 \mathrm{~s}$ and the longest in uncontrolled is $11.890 \mathrm{~s}$.

Table 10. Horisontal axis results

\begin{tabular}{ccccccc}
\hline & Unc & PID-PSO & PID-FA & PID-ICA & PID-BA & PID-ACO \\
\hline Kph & - & 212.400 & 83.264 & 101.076 & 93.764 & 94.347 \\
Kih & - & 27.100 & 49.521 & 0.608 & 0.5784 & 2.118 \\
Kdh & - & 152.000 & 8.852 & 92.423 & 85.763 & 73.231 \\
Overshoot (pu) & 46.100 & 49.100 & 41.765 & 38.535 & 25.912 & 32.892 \\
Undershoot (pu) & 22.300 & 22.100 & 14.773 & 13.841 & 12.723 & 10.473 \\
Settling time (s) & 11.890 & 0.500 & 0.223 & 0.324 & 0.241 & 0.254 \\
\hline
\end{tabular}

The vertical response results in Table 11 can be explained that of the 9 models, the worst model in tracking the position of the sun is an uncontrolled model. The highest overshoot value in PID-PSO is $46.490 \mathrm{pu}$ and the lowest value in PID-BA is $19.734 \mathrm{pu}$. The highest undershoot value in the uncontrolled model is $21.180 \mathrm{pu}$ and the lowest value in PID-ACO is $1.193 \mathrm{pu}$. The fastest completion time in PID-BA is $0.073 \mathrm{~s}$ and the longest in the uncontrolled is $9.230 \mathrm{~s}$.

In terms of the fastest completion time for both horizontal and vertical, the movement of PID controller using bat algorithm (BA) was the fastest among other artificial intelligence methods to point out the position [29]. Also did the simulation using PID-BA and compared it using uncontrolled. They concluded 
that PID-BA were better than the uncontrolled because the smallest elevation angle deviation was found in PID-BA controller. They suggested to use PID-BA for optimizing the result.

Table 11. Vertical axis results

\begin{tabular}{ccccccc}
\hline & Unc & PID-PSO & PID-FA & PID-ICA & PID-BA & PID-ACO \\
\hline Kpv & - & 287.2 & 134.05 & 124.89 & 56.322 & 134.053 \\
Kiv & - & 21.40 & 0.063 & 0.374 & 0.753 & 0.060 \\
Kdv & - & 132.5 & 92.391 & 83.798 & 81.227 & 43.385 \\
Overshoot (pu) & 46.02 & 46.49 & 40.830 & 35.823 & 19.734 & 24.473 \\
Undershoot (pu) & 21.18 & 20.48 & 14.474 & 12.384 & 1.193 & 3.762 \\
Settling time (s) & 9.23 & 0.18 & 0.152 & 0.181 & 0.073 & 0.462 \\
\hline
\end{tabular}

\section{CONCLUSION}

In this study dual axis photovoltaic tracking system is briefly described and the comparison of PID controller system using artificial intelligence is summarized. From the results and discussion, the result shows that among seven models, PID-BA was slightly better than the other methods in tracking the position of the sun. PID-BA can point at the fastest position even though it has a slightly undershoot smaller than PID-ACO on the horizontal axis.

\section{ACKNOWLEDGEMENTS} our research.

Thank you to the Ministry of Education and Culture of the Republic of Indonesia who has supported

\section{REFERENCES}

[1] A. A. Firdaus, "Design and simulation of neural network predictive controller pitch-Angle in permanent magnetic synchronous generator wind turbine variable pitch system," 1st International Conference on Information Technology, Computer, and Electrical Engineering (ICITACEE), 2014, pp. 346-350, doi: 10.1109/ICITACEE.2014.7065769.

[2] C. Ameur, S. Faquir, A. Yahyaouy, "Intelligent optimization and management system for renewable energy systems using multi-agent," IAES International Journal of Artificial Intelligence (IJ-AI), vol. 8, no. 4, pp. 352-359, 2019, doi: 10.11591/ijai.v8.i4.pp352-359.

[3] S. Faquir, A. Yahyaouy, H. Tairi and J. Sabor, "Energy management in a hybrid pv/wind/battery system using a type-1 fuzzy logic computer algorithm," International Journal of Intelligent Engineering Informatics, vol. 4, no. 13, pp. 229-244, 2016, doi: 10.1504/IJIEI.2016.080516.

[4] S. Faquir, A. Yahyaouy, H. Tairi and J. Sabor, "Implementing a fuzzy logic based algorithm to predict solar and wind energies in a hybrid renewable energy system," International Journal of Fuzzy System Applications, vol. 4, no. 3, pp. 10-24, 2015.

[5] A. A. Firdaus, R. T. Yunardi, E. I. Agustin, T. E. Putri, D. O. Anggriawan, "Short-term photovoltaics power forecasting using Jordan recurrent neural network in Surabaya," TELKOMNIKA Telecommunication Computing Electronics and Control, vol. 18, no. 2, pp. 1089-1094, 2020, doi: 10.12928/TELKOMNIKA.v18i2.14816.

[6] A. A. Firdaus, R. T. Yunardi, E. I. Agustin, S. D. N. Nahdliyah, T. A. Nugroho, "An improved control for MPPT based on FL-PSo to minimize oscillation in photovoltaic system," International Journal of Power Electronics and Drive System (IJPEDS), vol. 11, no. 2, pp. 1082-1087, 2020, doi: 10.11591/ijpeds.v11.i2.pp1082-1087.

[7] S. S. Raghuwanshi, V. Khare, "Sizing and implementation of photovoltaic water pumping system for irrigation," IAES International Journal of Artificial Intelligence (IJ-AI), vol. 7, no. 1, pp. 54-62, 2018, doi: 10.11591/ijai.v7.i1.pp54-62.

[8] A. Sfirat, A. Gontean, S. Bularka, "A new method for MPPT Algorithm implementation and testing, suitable for photovoltaic cells," Advances in Electrical and Computer Engineering, vol. 18, no. 3, pp. 53-60, 2018, doi: 10.4316/AECE.2018.03008.

[9] C. D. Rodriguez-Gallegos, O. Gandhi, S. K. Panda, T. Reindl, "On the PV tracker performance: Tracking the sun versus tracking the best orientation," IEEE Journal of Photovoltaics, vol. 10, no. 5, pp. 1474-1480, 2020, doi: 10.1109/JPHOTOV.2020.3006994.

[10] H. Mousazadeh, A. Keyhani, A. Javadi, H. Mobli, K. Abrinia, A. Sharifi, "A review of principle and sun-tracking methods for maximizing solar systems output," Renewable and Sustainable Energy Reviews, vol. 13, no. 8, pp. 1800-1818, 2009, doi: 10.1016/j.rser.2009.01.022.

[11] C. F. Gay, J. W. Yerkes, J. H. Wilson, "Performance advantages of two-axis tracking for large flat-plate photovoltaic energy systems," Proceedings of the 16th Photovoltaic Specialists Conference, San Diego, 1982, pp. 1368-1371.

Int J Artif Intell, Vol. 10, No. 4, December 2021: 901 - 909 
[12] D. H. Kusuma, M. Ali, N. Sutantra, "The comparison of optimization for active steering control on vehicle using PID controller based on artificial intelligence techniques," International Seminar on Application for Technology of Information and Communication (ISemantic), 2016, pp. 18-22, doi: 10.1109/ISEMANTIC.2016.7873803.

[13] A. Adhim, A. Musyafa, "Optimization of PID controller based on PSO for photovoltaic dual axis solar tracking in gresik location- East Java," Int. J. Eng. Technol. IJET- IJENS, vol. 16, no. 1, pp. 65-72, 2016.

[14] K., Rukslin, M. Ali, Askan, A. Parwanti, I. Cahyono, "Comparison of LFC optimization on micro-hydro using PID, CES, and SMES based firefly algorithm," 5th International Conference on Electrical Engineering, Computer Science and Informatics (EECSI), 2018, pp. 204-209, doi: 10.1109/EECSI.2018.8752733.

[15] M. Ali, F. Hunaini, I. Robandi, N. Sutantra, "Optimization of active steering control on vehicle with steer by wire system using imperialist competitive algorithm (ICA)," 3rd International Conference on Information and Communication Technology (ICoICT), 2015, pp. 500-503, doi: 10.1109/ICoICT.2015.7231475.

[16] M. Ali, Muhlasin, H. Nurohmah, A. Raikhani, H. Sopian, N. Sutantra, "Combined ANFIS method with FA, PSO, and ICA as steering control optimization on electric car," Electrical Power, Electronics, Communications, Controls and Informatics Seminar (EECCIS), 2018, pp. 299-304, doi: 10.1109/EECCIS.2018.8692885.

[17] A. Hassanien and E. Emary, "Bat algorithm (BA)," Swarm Intelligence, pp. 15-44, 2015.

[18] M. Dorigo and T. Stützle, "The ant colony optimization metaheuristic," Ant Colony Optimization, 2018.

[19] P. K. B, S. Jonnalagadda, M. Srihari, H. Bonothu, "Dual-axis solar tracker," Int. J. Recent Sci. Res., vol. 8, no. 2, pp. 15598-15603, 2017.

[20] S. S.-Soulayman, "Solar Azimuth angle in the tropical zone," J. Sol. Energy Res. Updat, vol. 4, no. 1, pp. 1-8, 2017.

[21] L. S. Mezher, "Position control for dynamic DC MOTOR with robust PID controller using MATLAB," International Journal of Advanced Trends in Computer Science and Engineering, vol. 8, no.3, 2019.

[22] A. A. Firdaus, O. Penangsang, A. Soeprijanto, U. P. D. Fajar, U.P., "Distribution network reconfiguration using binary particle swarm optimization to minimize losses and decrease voltage stability index," Bulletin of Electrical Engineering and Informatics (BEEI), vol. 7, no. 4, pp. 514-521, 2018, doi: 10.11591/eei.v7i4.821.

[23] J. Kennedy, R. C. Eberhart, "A discrete binary version of the particle swarm algorithm," 1997 IEEE International Conference on Systems, Man, and Cybernetics. Computational Cybernetics and Simulation, 1997, doi: 10.1109/ICSMC.1997.637339.

[24] M. Alb, P. Alotto, C. Magele, W. Renhart, K. Preis, B. Trapp, "Firefly Algorithm for finding optimal shapes of electromagnetic devices," IEEE Trans. Magn., vol. 52, no. 3, pp. 1-4, 2016, doi: 10.1109/TMAG.2015.2483058.

[25] T. A. Nugroho, R. S. Wijanarko, H. Setiadi, "Coordination of blade pitch controller and battery energy storage using firefly algorithm for frequency stabilization in wind power systems," TELKOMNIKA Telecommunication Computing Electronics and Control, vol. 17, no. 2, pp. 1014-1022, 2019, doi: 10.12928/TELKOMNIKA.v17i2.9162.

[26] M. Elgamal, N. Korovkin, A. Elmitwally, A. A. Menaem, Z. Chen, "A Framework for profit maximization in a grid-connected microgrid with hybrid resources using a novel rule base-BAT algorithm," IEEE Access, vol. 8, pp. 71460 - 71474, 2020, doi: 10.1109/ACCESS.2020.2987765.

[27] A. M. Eltamaly, M. S. Al-Saud, A. G. Abokhalil, "A novel bat algorithm strategy for maximum power point tracker of photovoltaic energy systems under dynamic partial shading," IEEE Access, vol. 8, pp. 10048-10060, 2020, doi: 10.1109/ACCESS.2020.2964759.

[28] V. M. Joy, S. Krishnakumar, "Optimal design of adaptive power scheduling using modified ant colony optimization algorithm," International Journal of Electrical and Computer Engineering (IJECE), vol. 10, no. 1, pp. 738-745, 2020, doi: 10.11591/ijece.v10i1.pp738-745.

[29] M. Ali, T. Fahmi, D. W. Khaidir, H. Nurohmah, Budiman, "Optimizing single axis tracking for bat algorithm-based solar cell," Frontier Energy System and Power Engineering, vol. 2, no. 2, pp 1-5, 2020. 